\title{
Educação escolar e população do campo Por um ensino de português bidialetal
}

Rosenildo da Costa Pereira*

RESUMO: Este texto tem como objetivo analisar o efeito "devastador" do ensino de português padrão no processo ensino-aprendizado e no rebaixamento da identidade linguística dos alunos das classes populares do campo da Amazônia Paraense. Os pressupostos teóricos e metodológicos que embasaram a elaboração deste trabalho de pesquisa foram os mais renomados hoje no campo de estudo da sociolinguística no Brasil como: Bagno (1999, 2006), Bortoni-Ricardo (2005), Couto (1991), Silva (2004), Soares (2002), entre outros, que guiaram, orientaram e fundamentaram nossa argumentação. $\mathrm{O}$ estudo bibliográfico aponta que a escola não reconhece os diferentes dialetos dos sujeitos do campo.

Palavras-chave: Ensino de língua portuguesa. Diversidade linguística. Educação do campo na Amazônia Paraense.

\section{School based education and the rural population}

The teaching of Portuguese through two dialects

\begin{abstract}
The objective of this text is to analyse the "devastating" effect of the teaching of standard Portuguese on the teaching - learning process and on the relegation of linguistic identity of students from the lower classes in rural Amazonian zones in the state of Para. The theoretical and methodological assumptions on which this piece of research is based are among the most renowned today in the field of sociolinguistic studies in Brazil, such as: Bagno $(1999,2006)$, Bortoni - Ricardo (2005), Couto (1991), Silva (2004), Soares (2002),
\end{abstract}

* Mestre em educação. Professor do Programa ProJovem Campo - Saberes da Terra, no município de Abaetetuba. Pesquisador do Grupo de Estudo, Pesquisa e Extensão “Sociedade, Estado e Educação: ênfase nos governos municipais e educação do campo" (GEPESEED) e integrante do projeto de pesquisa "Travessias, identidades e saberes das águas - Cartografia de saberes de populações ribeirinhas", ambos da Universidade Federal do Pará (UFPA) - Campus de Abaetetuba. Abaetetuba/PA - Brasil. E-mail: <rosenildocosta@bol.com.br>. 
among others, which guide, orientate and on which are based our arguments. The bibliographical studies show that schools do not recognise the different dialects among the rural subjects.

Key words: Portuguese language teaching. Linguistic diversity. Rural education in the Amazon region of the State of Para.

\section{Educación escolar y población del campo Por una enseñanza bidialectal del portugués}

RESUMEN: Este texto tiene el objetivo de analizar el efecto "devastador" de la enseñanza del portugués estándar en el proceso de enseñanza/aprendizaje y en la depreciación de la identidad lingüística de los alumnos de las clases populares del campo de la zona amazónica del estado de Pará. Las referencias teóricas y metodológicas que sirven de base para la elaboración de este trabajo de investigación son las más reconocidas hoy en el campo de estudio de la sociolingüística en Brasil. Así, Bagno (1999, 2006), Bortoni-Ricardo (2005), Couto (1991), Silva (2004), Soares (2002), entre otros, guiaron, orientaron y fundamentaron nuestra argumentación. El estudio bibliográfico señala que la escuela no reconoce los diferentes dialectos de los sujetos del campo.

Palabras clave: Enseñanza de la lengua portuguesa. Diversidad lingüística. Educación del campo en la zona amazónica del estado de Pará.

\section{Education scolaire et population rurale \\ Pour un enseignement du portugais bidialectal}

RÉSUMÉ: Cet article vise à analyser l'effet "devastateur" de l'enseignement du portugais standard dans le processus d'enseignement-apprentissage et le rabaissement de l'identité linguistique des éléves des classes populaires du milieu rural du Para Amazonique. Les hypothéses théoriques et méthodologiques qui ont soutenu le développement de ce travail de recherche sont celles des auteurs les plus renommés aujourd'hui en ce qui concerne les études socio-linguistiques au Brésil comme : Bagno (1999, 2006), 
Bortoni-Ricardo (2005), Couto (1991), Silva (2004), Soares (2002), entre autres, auteurs qui ont guidé, orienté et étayé notre argumentation. L'étude bibliographique souligne que l'école ne reconnait les différents dialectes des sujets en milieu rural.

Mots-clés: Enseignement de la langue portugaise. Diversité linguistique. Education en milieu rural dans le Para Amazonique.

\section{Introdução}

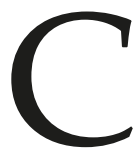

riou-se no Estado brasileiro, durante anos, a convicção de que todos seus habitantes são homogêneos. O dialeto padrão da língua portuguesa foi pensado e formulado de forma igual para todos, levando em consideração os princípios hegemônicos da classe dominante, desconsiderando a especificidade local e regional do dialeto não-padrão do uso da língua falada pela população brasileira.

Entretanto, o Brasil concentra em seu território uma imensa população que se diferencia pela característica heterogênea, que se dinamiza por meio das culturas das classes sociais que habitam o espaço geográfico.

Contribuindo para essa multiculturalidade estão as populações do campo da Amazônia Paraense, amplamente distribuída no espaço geográfico, e nesse espaço manifestam/expressam uma diversidade cultural extraordinária. Diversidade que é possível observar de maneira específica no modo de falar, nos costumes, dentre outros aspectos da especificidade da realidade da população local.

O objetivo deste texto é argumentar em favor de um ensino de língua portuguesa que possa atender, eventualmente, as reais necessidades de falares do cotidiano da educação das populações campesinas do Estado do Pará/ Região Amazônica, isto é, uma perspectiva de ensino fundamentado no bidialetalismo, que terá como propósito fundamental a valorização dos aspectos linguísticos identitários do uso da língua falada da realidade concreta dos sujeitos neste universo específico do espaço geográfico brasileiro.

O recorte deste trabalho gira em torno de a escola privilegiar a postura da língua falada dos educandos das classes populares da Amazônia, ou seja, o dialeto não-padrão do uso da língua falada, mostrando que na realidade local as formas de uso da língua falada é bastante variável e que, além do dialeto padrão, tem-se uma infinidade de diferentes dialetos que extrapolam a unicidade da língua.

Neste estudo, os procedimentos metodológicos adotados foram: estudo bibliográfico, fundamentado em obras de autores com renomada experiência no campo da 
sociolinguística, como Bagno (1999, 2006), Bortoni-Ricardo (2005), Couto (1991), Oliveira (2010), Silva (2004), Soares (2002) entre outros.

Análise documental, centrada no resultado do Índice de Desenvolvimento da Educação Básica (Ideb) divulgado pelo Ministério da Educação (MEC) no ano de 2013, cuja análise visou inter-relacionar o conceito obtido em Língua Portuguesa no Brasil, sobretudo no Estado do Pará, e o que os teóricos da sociolinguística defendem como proposta de ensino da disciplina, principalmente no que diz respeito à diversidade linguística do País.

Este texto divide-se em três partes. Em primeiro lugar, esboçamos, de forma breve, o ensino de português no espaço escolar brasileiro, com características de um ensino a serviço dos caprichos da classe hegemônica, que busca ratificar a todo momento o dialeto padrão. Posteriormente, mencionaremos uma política linguística, na perspectiva de um ensino de português que atenda a especificidade da educação das populações do campo da Amazônia Paraense, ou seja, um ensino bidialetal. Finalizaremos este ensaio com as considerações finais, que demonstram o papel de cada um de nós, educadores comprometidos com a educação das classes populares, alertando e conscientizando os educandos sobre a imensa diversidade linguística no território brasileiro e que não há razões legítimas para discriminar os falantes do dialeto não-padrão.

\section{O ensino de português que tem permeado o contexto escolar}

Vivemos em um país marcado historicamente pela desigualdade social de diversa natureza. Prova dessa desigualdade é possível observar, de maneira específica, no modelo tradicional de ensino de português no contexto do espaço escolar brasileiro, com a valorização da linguagem de uma parcela restrita da sociedade brasileira, enquanto a cultura social da maioria da população é massificada em função desta.

A educação escolar brasileira esteve, durante muito tempo, mergulhada em uma epistemologia de ensino do dialeto padrão, considerado até então como a gramática normativa da língua portuguesa.

O resultado desta perspectiva de ensino de português é mostrado nos dados estatísticos educacionais divulgados pelo Índice de Desenvolvimento da Educação Básica (IDEB-2013) que avalia o desempenho dos alunos em Língua Portuguesa, principalmente, comparando a média nacional, com a média do Estado do Pará. 
Tabela 1 - IDEB

\begin{tabular}{l|c|c|c}
\hline & $\begin{array}{c}\text { Séries Iniciais } \\
\text { do Ensino } \\
\text { Fundamental }\end{array}$ & $\begin{array}{c}\text { Séries Finais } \\
\text { do Ensino } \\
\text { Fundamental }\end{array}$ & Ensino Médio \\
\hline Brasil & 5,2 & 4,2 & 3,7 \\
\hline Estado Pará & 4,0 & 3,6 & 2,9 \\
\hline
\end{tabular}

Fonte: IDEB-2013

A forma como a língua portuguesa tem sido ensinada nas escolas, desarticulada da realidade local, tem contribuído para o baixo índice de desenvolvimento educacional. O que nos remete a pensar que o ensino da língua não tem cumprido o seu devido papel enquanto disciplina obrigatória da educação básica.

Com isso, percebe-se que nossos representantes legais de épocas passadas e os que hoje estão à frente do Brasil nunca deram atenção especial para os conhecimentos sociolinguísticos da classe trabalhadora brasileira e muito menos aos saberes linguísticos dos sujeitos do campo da Amazônia Paraense, por considerarem que o dialeto padrão da língua portuguesa é a que se deve ensinar nas escolas. As demais formas de expressões são de pronúncias ruins, de estigmas baixos, de pertencimento de categorias sociais "não cultas". O que tem fortalecido ainda mais o preconceito linguístico entre as regiões e classes sociais do Estado brasileiro.

Por estas e outras razões de cunho preconceituoso é que os gramáticos defendem que o dialeto padrão é que tem que ser ensinado nas escolas. Ela é a língua que mais se assemelha ao português falado em Portugal. Entretanto, este dialeto não tem nada a ver com "o português" dos brasileiros.

Analisando todo o contexto histórico-social da colonização do Brasil é válido salientar que essa política linguística foi construída de "cima para baixo", uma vez que não considerou a heterogeneidade do povo que aqui vive quanto à questão referente ao dialeto não-padrão do uso da língua falada. Considerando que,

$$
\begin{aligned}
& \text { se se tratar de uma fase histórica em que predominam as forças conservadoras, } \\
& \text { se optará pela comunicação geral, pela unificação. Mas será uma unificação for- } \\
& \text { çada de cima para baixo, que tentará impor a linguagem do passado (que tem } \\
& \text { "tradição") [...] (COUTO, 1991, p. 53). }
\end{aligned}
$$

Este modelo linguístico contribuiu significativamente com o aprendizado escolar dos alunos que faziam parte do regime escolar daquela época, visto que uma minoria da população era quem frequentava este espaço. Sendo assim, seu conhecimento linguístico se aproximava muito bem daquele exigido pela unidade de ensino vigente no momento histórico-social. 
Silva (2004) afirma que, até meados da década de 1960, uma parcela restrita da sociedade brasileira chegava à escola, que atendia satisfatoriamente as expectativas daqueles discentes no que se refere ao ensino de língua portuguesa, uma vez que esta reproduzia os saberes linguísticos da sociedade capitalista brasileira. Considerando que “a norma que se deve ensinar na escola é a culta. Ela é a linguagem mais próxima das classes dominantes" (COUTO, 1991, p. 92).

A escola estava a serviço dos preceitos da classe dominante brasileira, que ratificava a todo instante a cultura erudita dos poucos que frequentavam o espaço escolar formal.

\section{O que defendemos como política linguística}

Considerando que as instituições de ensino do Brasil, durante décadas, têm valorizado o ensino do português padrão, uma vez que recebiam como alunado os filhos dos grupos que compõem a classe dominante, que já chegavam a elas com uma bagagem cultural bastante rica, dado pelo acesso aos bens cultuais de suas famílias, pode-se dizer que eles não encontravam, portanto, dificuldades de aprendizagem nessa disciplina, uma vez que,

Até meados deste século, até talvez a década de 1960, à escola chegava uma minoria. A escola dava conta dessa minoria e atendia às expectativas dos segmentos dominantes da sociedade. No que se refere à língua portuguesa, os indivíduos escolarizados, cumprida a escolaridade, dominavam, ou se acreditava que dominassem, o padrão lingüístico designado por tradição como o "correto" (SILVA, 2004, p. 74)

Com o passar do tempo, por volta de meados da década de 1960, a classe trabalhadora brasileira começou a pressionar o Estado para construir escolas que pudessem atender às reais necessidades da educação de seus filhos, possibilitando, neste sentido, o acesso à escolarização formal aos que se encontravam excluídos do processo educativo formal.

A partir dessa década, foi ampliado o ensino no Brasil. Para atender às exigências da população trabalhadora local, as escolas passaram a receber alunos de diferentes grupos sociais. Os discentes, ao chegarem às unidades escolares, tinham um choque cultural, visto que se deparavam com situações que para eles eram considerados de outro universo. Um exemplo é a questão da linguística, com o uso do dialeto padrão, pois tinham que se adaptar à verdadeira realidade do ensino oferecido pela escola, e não a escola a eles.

Silva (2004, p. 74) destaca que “a 'crise', a 'falência' do ensino da língua portuguesa de que venho falando são, fundamentalmente, não apenas, é claro, consequência de uma 
inadequação do objetivo do seu ensino em face da realidade". Soares afirma que "escola que seria para o povo é, na verdade, contra o povo" (2002, p. 10).

Neste sentido, os saberes linguísticos oriundos dos filhos da classe trabalhadora da região Amazônica eram e continuam sendo menosprezados pela vertente de ensino que, durante muito tempo, vem desconsiderando a diversidade econômica, cultural e social dos diferentes sujeitos que vivem no contexto social da Amazônia Paraense. Como bem afirma Veiga-Neto (2003, p. 7):

Assim, a modernidade esteve por longo tempo mergulhada numa epistemologia monocultural. E para dizer de forma sintética, a educação era entendida como o caminho para o atingimento das formas mais elevadas da cultura, tendo por modelo as conquistas já realizadas pelos grupos sociais mais educados e, por isso, mais cultos.

No Brasil não são poucas as formas de uso da língua, pois cada região possui uma específica forma de expressar essa maneira diferente, que neste caso é o conhecido como dialeto $^{1}$. Dialeto que está presente principalmente na vida cotidiana dos indivíduos amazônidas. No entanto, o dialeto padrão da língua portuguesa desconsidera o uso dessa variação linguística, ou seja, ele passa a ser considerado como maneira "errada" do uso dialetal padrão, considerando que

[...] não se percebe no interior escolar, tendo seus padrões culturais e lingüísticos ignorados ou desprezados como "errados", avaliados etnocentricamente pelos padrões lingüístico-culturais dos dominantes, na pretensa crença de que o educando das camadas populares apresenta familiaridade com conceitos e informações próprias do universo cultural daqueles. Nega-se, assim, o direito a diferença (RODRIGUES, 2007, p. 81-82).

A partir da perspectiva de que os sujeitos amazônicos têm valores e identidades culturais próprias e que, por circunstâncias da educação escolar brasileira, vêm sofrendo preconceitos em seu modo de falar, estigmatizando sua linguagem específica no interior do espaço escolar formal, defendemos uma proposta educativa que passe pela inversão do modelo tradicional do ensino de português, isto é, um ensino que perpasse primeiramente pelo conhecimento "linguageiro" que os sujeitos do campo da região Amazônica já utilizam.

A esse respeito afirma Rodrigues (2007, p. 77)

[...] esboçamos algumas reflexões sobre identidade e política lingüística, preconizando o ensino bidialetal com uma alternativa para assegurar o respeito aos dialetos populares e a aceitação de sua utilização tanto na escola como fora dela, vendo o dialeto padrão não como a única e "correta" possibilidade de expressão, mas apenas como mais um instrumento de interação, necessário em alguns contextos, enquanto em outros não. 
Neste sentido, necessitamos compreender que a escola precisa valorizar toda e qualquer forma de conhecimento presente na realidade em que está inserida, buscando principalmente valorizar o saber dialetal dos indivíduos que fazem parte dela.

De certa forma, como afirmam Cardoso, Portela e Santos (2008, p. 122 - 123):

A escola, urgentemente, precisa reconhecer as variações lingüísticas dos seus discentes e aceitar que a língua é heterogênea, e que, portanto, as diferenças não são erros por isso elas devem ser estudadas paralelas, como à norma padrão e não ridicularizadas, como de fato são. Não há duvidas de que a norma padrão é a de maior prestígio social, mas essa questão deve ser explicada de forma reflexiva e não imposta.

É importante ressaltar também a especificidade da linguagem da população ribeirinha Amazônica, por meio da utilização de dialetos que, segundo a Revista Memória e Revitalização Identitária (2009, p.10), em sua maioria, tem origem tupi e demonstram a resistência do povo ribeirinho.

Como conhecemos a especificidade da linguagem da população Amazônica, com o uso de variedades de linguagens que possuem traços de identidade de origem indígena, demonstrando que, além desta, a população sofreu influência linguística de outros povos que passaram pela região no período colonial. Daí o motivo de toda essa diversidade linguística presente no contexto Amazônico Paraense.

A educação escolar brasileira deve estar preocupada com a valorização dos aspectos identitários, que fazem parte da vida cotidiana dos sujeitos que vivem e habitam na região Amazônica Paraense. Contudo, não se trata de dissociar o conhecimento linguístico da realidade urbana do da rural, mas sim valorizar toda e qualquer forma de saber dialetal existente na realidade brasileira.

Neste caso, valorizar de forma particular as experiências culturais dos sujeitos que vivem na região ribeirinha Amazônica, bem como dos moradores da zona urbana, pois é esse tipo de política de educação linguística que defendemos para a realidade educacional do Brasil e, mais precisamente, para o espaço Amazônico Paraense. Uma educação que perpasse pelo respeito de toda complexidade sociolinguística dos diferentes educandos.

Trabalhando em sala de aula com os diferentes dialetos, estaremos garantindo o direito dos alunos das classes populares ao aprendizado do dialeto padrão e, sobretudo, valorizando os diferentes dialetos. Isso "evitaria" o preconceito linguístico contra as demais formas de expressão das populações brasileiras, uma vez que os educandos estariam informados sobre a heterogeneidade de dialetos do País.

O ensino do dialeto padrão, como diz Candau (2008, p. 53-54): "relaciona-se também ao conhecimento e à promoção entre os diferentes saberes, conhecimentos e práticas dos diferentes grupos culturais". Entretanto, o dialeto padrão vem menosprezando no espaço escolar formal a questão dialetal dos sujeitos Amazônicos. 
As escolas do Brasil precisam exercitar a contextualização dos conhecimentos linguísticos dos educandos à prática educativa da sala de aula, afirmando, assim, as identidades e valores culturais específicos desses sujeitos. Valorizar a especificidade da realidade local significa nada mais que respeitar, primordialmente, o uso da variação dialetal que trazem do universo ribeirinho da sua própria realidade local, pois

Ensinar exige respeito aos saberes dos educandos... o dever de não só respeitar os saberes com que os educandos, sobretudo os das classes populares, chegam a ela - saberes socialmente construídos na prática comunitária - mas também, como há mais de trinta anos venho sugerindo, discutir com os alunos a razão de ser de alguns desses saberes em relação com o ensino dos conteúdos. (FREIRE, 1996, p. 30).

Reforçando a mesma ideia, Paulo Freire (2004, p. 24) destaca que "o que a tolerância autêntica demanda de mim é que respeite o diferente, seus sonhos, suas ideias, suas opções, seus gostos, que não o negue só porque é diferente. O que a tolerância legítima termina por me ensinar é que, na sua experiência, aprendo com o diferente".

Analisando este contexto, a escola tem que estar atenta para a aceitação do novo, da bagagem cultural e social que o aluno traz da realidade em que vive, e que precisa ser, evidentemente, trazida para a prática educativa da sala de aula, utilizando toda essa bagagem cultural como recurso pedagógico para o bom desenvolvimento do processo de ensino aprendizagem. No dizer de Silva (2004, p. 74):

A escolaridade vem de fato popularizando-se (não tanto, nem como desejariam muitos, entre esses eu). Esse fator leva para a escola a diversidade de línguas, a diversidade de dialetos, a diversidade de normas. A instituição escolar, no entanto, por razões ideológicas, tenta remar contra a maré: a imposição do padrão idealizado como o "correto" é ainda o objetivo que persegue.

Aprofunda-se, assim, a ideia de que a escola deve valorizar a diversidade do saber cultural dos seus educandos, considerando que "nossa escola não reconhece a existência de uma multiplicidade de variedades de português e tenta impor a norma-padrão sem procurar saber em que medida ela é na prática uma 'língua estrangeira' para muitos alunos, senão para todos" (BAGNO, 2006, p. 29).

É preciso reconhecer a importância de a escola valorizar em seu espaço de sala de aula a diversidade sociocultural dos sujeitos que vivem no campo ribeirinho da Amazônia Paraense, mostrando - lhes que são pessoas com saberes identitários próprios e com toda uma diversidade cultural que os cerca e, principalmente, pelo seu modo diferente e particular de se expressar no cotidiano, reforçando cada vez mais que a sua linguagem é importante e necessária para o processo comunicativo na sociedade e no meio social em que estão inseridos. 
Segundo Oliveira (2010, p. 43),

\begin{abstract}
Ajudar o estudante a aprender a se comportar linguisticamente em diversas situações de interação social é o objetivo principal das aulas de português, que não deveriam ter como foco principal o ensino da gramática normativa por meio da nomenclatura que a descreve de forma inconsistente. Ensina-se português aos brasileiros para ajuda-los a desenvolver sua competência comunicativa.
\end{abstract}

Com isso, a escola passa a cumprir seu verdadeiro e devido papel de agente promissor de conscientização de que não existe uma única língua falada no Brasil, bem como acaba por elevar a auto-estima dos educandos quanto ao uso do dialeto não-padrão, demonstrando que seu conhecimento dialetal é tão importante quanto o dialeto padrão da língua portuguesa.

\title{
Considerações Finais
}

Enquanto nosso sistema educacional não reconhece a diversidade linguística dos sujeitos que a ele chega, resta a todos nós, educadores comprometidos com a educação das camadas populares do Brasil, propagar aos nossos alunos a convicção de que não foi cientificamente comprovado que, diante da variedade da língua, exista uma que seja superior ou inferior, "melhor" ou pior que outra. Todas têm sua utilidade, de acordo com o contexto onde estão inseridas, e a escola, enquanto instituição formadora, precisa trabalhar com a diversidade de modos de falar, característica de um país marcado pela heterogeneidade no linguajar de sua população.

Há que conscientizar os alunos das classes populares de que na escola, muitas vezes, são vítimas de preconceito linguístico, pelo seu modo de falar, o que, na realidade concreta, não possui nenhuma fundamentação legal, uma vez que, no Brasil, existe uma imensa diversidade linguística, o que torna o País cada vez mais heterogêneo.

Para Soares (2002, p. 48):

[...] a solução estaria numa mudança de atitudes de professores, e da população em geral, que deveriam ser educados para compreender que todos os dialetos são igualmente válidos, corretos, e que não há razões legítimas para discriminação de falantes que usam dialetos não-padrão.

Os educadores, principalmente os professores de língua portuguesa, que são os propagadores do dialeto padrão, precisam pensar e repensar sobre suas práticas educativas, se estão contribuindo realmente com a transformação da sociedade em seus aspectos culturais, econômicos, políticos e sociais.

Ninguém melhor do que eles, estudiosos desta área do conhecimento, para alertar os alunos de que seu conhecimento dialetal é tão válido quanto qualquer outro conhecimento linguístico no território brasileiro, ratificando a identidade cultural dos sujeitos. 
É verdade que não podemos mudar este sistema tradicional de ensino do dia para a noite, mas se cada um de nós, educadores, com o poder educativo de que dispomos, fizermos a diferença no meio social em que estamos inseridos, enfatizando que é possível ensinar português usando os diferentes saberes dialetais, reforçaremos em nossos alunos que o português brasileiro, como diz Couto (1991), é o português falado por cada um de nós, brasileiros.

Recebido em agosto de 2015 e aprovado em março de 2016

\section{Notas}

1 Dialeto discutido neste texto se refere a "um termo usado há muitos séculos, desde a Grécia antiga, para designar o modo característico de uso da língua num determinado lugar, região, província etc (BAGNO, 2007, p. 48).

\section{Referências}

BAGNO, Marcos. A Língua de Eulália: novela sociolingüística. 15. Ed. São Paulo: Contexto, 2006.

. Preconceito Lingüístico. São Paulo: Loyola, 1999.

Nada na Língua é por Acaso: Por uma pedagogia da variação lingüística. São Paulo: Parábola Editorial, 2007.

Bortoni-Ricardo, Stella Maris. Nós cheguemu na escola, e agora? Sociolingüística na sala de aula. São Paulo: Parábola Editorial, 2005.

BRASIL. Índice de Desenvolvimento da Educação Básica-IDEB, 2013.

CANDAU, Vera Maria. Direitos Humanos, educação e interculturalidade: as tensões entre igualdade e diferença. Revista Brasileira de Educação, v. 13, n. 37, p. 45-56, jan./abr. 2008.

CARDOSO, M. P. S; PORTELA, L. M. F; SANTOS, R. S. Estudo Fonético-Fonológico das Falas das Comunidades Rurais-Ribeirinhas. In: OLIVEIRA, Ivanilde Apoluceno de (org.). Cartografias ribeirinhas: saberes e representações sobre práticas sociais cotidianas de alfabetizandos amazônidas. 2. Ed. Belém: EDUEPA, 2008.

COMISSÃO PASTORAL DA TERRA. Memória e Revitalização Identitária. Ananindeua: CPT região Guajarina, №2, 2009.

COUTO, Hildo Honório do. O que é português brasileiro. 6. Ed. São Paulo: Brasiliense, 1991.

FREIRE, Paulo. Pedagogia da Autonomia: saberes necessários à prática educativa. 34. Ed. São Paulo: Paz e Terra, 1996. 
Pedagogia da Tolerância. São Paulo: UNESP, 2004.

OLIVEIRA, Luciano Amaral. Coisas que todo professor de português precisa saber: a teoria na prática. São Paulo: Parábola Editorial, 2010.

RODRIGUES, D. S.; Escola, Linguagem e Camadas Populares: uma questão de identidade e cidadania. In: SILVA, G. P.; CANALI, H. H. B.; RODRIGUES, D. S.; ARAÚJO, M. N. C. (ORGS). 2007. Educação do Campo na Amazônia: uma experiência. Edufpa, Belém.

SILVA, Rosa Virgínia Mattos. O português são dois: novas fronteiras, velhos problemas. São Paulo: Parábula Editorial, 2004.

SOARES, Magda. Linguagem e Escola: uma perspectiva social. 17. Ed. São Paulo: Ática, 2002.

VEIGA-NETO, Alfredo. Cultura, culturas e educação. In: Revista Brasileira de Educação, ANPED, n. 23, p. 5-15, maio/jun./ago. 2003. 